\title{
AOR
}

Selected Papers of \#AolR2019:

The $20^{\text {th }}$ Annual Conference of the Association of Internet Researchers Brisbane, Australia / 2-5 October 2019

\section{\#METOO AND INTERSECTIONALISM: "RADICAL COMMUNITY HEALING" OR "VOYEURISTIC TRAUMA PORN?"}

Verity Trott

Monash University

In October 2017, millions of people reflected on their experiences of sexual abuse and harassment, publicly sharing their testimonials in an expression of global vulnerability using the hashtag \#MeToo. Social media platform Twitter became the site of an international phenomenon with reports documenting that in less than a month \#MeToo had been tweeted over 1.7 million times across 85 countries (Park, 2017). However, amongst all of the testimonials emerged an undercurrent of those who were absent from the movement. Many of the tweets portrayed the angst and distress individuals experienced in their decision to participate, indicating the emotional and psychological costs of engaging with online feminist campaigns. Further, some tweets questioned the efficacy of the movement; expressing frustration at the re-appropriated nature of the campaign and the collective feeling of an "intersectional betrayal" by white women and feminists who dominated the mainstream media reporting of the movement.

The phrase "me too" can be traced back to 2006 when African-American activist Tarana Burke used the phrase to raise awareness of the pervasiveness of sexual violence against women. It was used between survivors to let them know they were not alone. More than a decade later, the hashtag spread virally after American actress Alyssa Milano tweeted \#MeToo and accused film producer Harvey Weinstein of sexual misconduct. The shift from a private exchange of solidarity to a public testimonial is crucial in understanding the costs associated with participation and how the action was reappropriated, consequently overlooking the affective labour of the black woman who laid the foundation.

A growing body of literature is developing in attempt to conceptualise the large-scale impact of what has potentially been one of the most highly publicised movements in the connective era (Kunst et al., 2018; Lilja \& Johansson, 2018; Mendes et al., 2018; Onwuachi-Willig, 2018; Roy, 2018; Sharoni, 2018; Zarkov \& Davis, 2018). Much of this

Suggested Citation (APA): Trott, V. (2019, October 2-5). \#MeToo and Intersectionalism: "Radical Community Healing" or “Voyeuristic Trauma Porn?". Paper presented at AoIR 2019: The $20^{\text {th }}$ Annual Conference of the Association of Internet Researchers. Brisbane, Australia: AolR. Retrieved from http://spir.aoir.org. 
research examines \#MeToo as a secondary case study, considering the broad meanings of the large-scale movement and using a more local and defined protest to flesh out the examination in finer detail. This is understandable given the radical pace of the movement and its global spread. Many of the impacts and the peripheral actions that have been energised by \#MeToo are yet to be fully realised. This paper centres the \#MeToo movement, providing an intersectional critique and drawing attention to the absent or overlooked voices as well as the additional costs of participation that prevent less privileged women from participating.

The paper adopts an intersectional framework, as conceptualised by Kimberle Crenshaw (1991), to analyse the intersectional issues within the \#MeToo movement. Crenshaw (1991:1246) in her research into violence against women of colour, develops the concept of intersectionality to denote the ways in which "systems of race, gender, and class domination converge" and how the patterns of subordination intersect in women's experiences. Crenshaw (1991:1249) identifies how another dimension of disempowerment can be a result of the imposition of one subordinal factor and how it interacts with a pre-existing vulnerability. This results in unique intersectional concerns that are often not addressed by social movement groups. Further, Crenshaw (1991) demonstrates how feminist and antiracist discourses not only fail to address the issues that arise at the intersection of gender and race but can unintentionally further reproduce the subordination of both. Crenshaw's notion of intersectionality is used as a conceptual framework for the analysis of the narratives that arose from the tweets collected for this research. The tweets demonstrate some of the issues that women of colour experienced within the movement as well as the additional challenges that arose surrounding the inclusion of queer women and women with disabilities.

Adrienne Rich's (1980) research problematizing the often default assumption of heterosexuality is also employed to expand the analysis into looking at queerness within \#MeToo and how the movement adopted a heterosexual framework. Similarly, trans scholar and writer Julia Serano $(2007,2013)$ also identifies how feminist movements have often been unwelcoming to trans folk and particularly transwomen. Trans folk experience both traditional and oppositional sexism, which contribute to the high levels of sexual harassment and assault they experience, making them an exceptionally vulnerable community (Serano, 2007, 2013). Together, this literature helps to inform the intersectional analysis provided within this article.

The paper draws on a large data set of 241,361 tweets collected on the platform DiscoverText from the first three days of the \#MeToo movement and combines content, discourse and social network analysis to examine the narratives related to participation. Specifically, the paper highlights the experiences and reflections of users who selfidentified as queer, disabled, or a person of colour within their tweets. In addition, a social network analysis is used to visualise a snapshot of the affective publics that arose at the beginning of the movement and to illustrate how systems of oppression converged.

This research foregrounds the intersectional concerns that result from the scale and reach of the millions of testimonials suspended online that constitute the \#MeToo movement. It further highlights how the many voices and stories that have circulated the 
online sphere obscure the absence and recognition of marginalised women and those who are already more vulnerable in regards to experiencing sexual assault (OnwuachiWillig, 2018). The findings illustrate how the original creator of the term 'me too', Tarana Burke, was extremely distanced from the centre of the movement in the first three days. In comparison, the Women's March twitter account dominated the protest network on the first day and maintained a central and influential position. Further, the findings document the intersectional differences in relation to how victimhood is afforded; sexual violence is experienced; and how access to resources and support networks are granted. Last, the analysis found key themes including a distrust of white allies and a need for a more inclusive feminist movement.

\section{References}

Crenshaw, K. (1991). Mapping the Margins: Intersectionality, Identity Politics, and Violence against Women of Color. Stanford Law Review, 43(6), 1241-1299.

Kunst, J., Bailey, A., Prendergast, C., \& Gundersen, A. (2018). Sexism, rape myths and feminist identification explain gender differences in attitudes toward the \#metoo social media campaign in two countries. Media Psychology. 1-26.

DOI: $\underline{10.1080 / 15213269.2018 .1532300}$

Lilja, M., \& Johansson, E. (2018). Feminism as power and resistance: An inquiry into different forms of Swedish feminist resistance and anti-genderist reactions. Social Inclusion, 6(4), 82-94.

Mendes, K., Ringrose, J., \& Keller, J. (2018). \# MeToo and the promise and pitfalls of challenging rape culture through digital feminist activism. European Journal of Women's Studies, 25(2), 236-246.

Onwuachi-Willig, A. (2018). What about \#UsToo?: The Invisibility of Race in the \#MeToo Movement. Yale Law Journal Forum, 128, 105-120. Retrieved from https://www.yalelawjournal.org/forum/what-about-ustoo.

Park, A. (2017, December 6). \#MeToo reaches 85 countries with 1.7M tweets. CBS News, Retrieved from https://www.cbsnews.com/news/metoo-reaches-85-countrieswith-1-7-million-tweets/

Rich, A. (2003). Compulsory Heterosexuality and Lesbian Existence [1980]. Journal of Women's History, 15(3), 11-48. 
Roy, S. (2018). \#MeToo is a Crucial Moment to Revisit the History of Indian Feminism. Lecture Transcript. Retrieved from: https://www.cetri.be/MeToo-Is-A-Crucial-Momentto?lang=fr

Sharoni, S. (2018). Speaking up in the age of\# MeToo and persistent patriarchy or what can we learn from an elevator incident about anti-feminist backlash. Feminist Review, 120(1), 143-151.

Serano, J. (2007). Whipping Girl: A Transsexual Woman on Sexism and the Scapegoating of Femininity. Seal Press: Seattle.

Serano, J. (2013). Excluded: Making Feminist and Queer Movements More Inclusive. Seal Press: Seattle.

Zarkov, D., Davis, K., (2018). Ambiguities and Dilemmas around \#MeToo: \#ForHow long and \#WhereTo?. European Journal of Women's Studies, 25(1), 3-9. 